\title{
Negotiation of Meaning in Required and Optional Information Exchange Tasks: Discourse Issues
}

\author{
Zohre Mohamadi \\ Department of Literature and Foreign languages, College of English Language Translation, Karaj Branch , Islamic University of Karaj, Alborz, Iran \\ E-mail: zohre.mohamadi@kiau.ac.ir
}

Received: $10-07-2014$

Accepted: 01-09-2014

Published: 01-01-2015

doi:10.7575/aiac.ijalel.v.4n.1p.95

URL: http://dx.doi.org/10.7575/aiac.ijalel.v.4n.1p.95

\begin{abstract}
It is widely argued that different types of tasks facilitate the acquisition of communicative language to different degrees through providing different contexts for the occurrence of negotiation of meaning which is believed to have facilitative role in language acquisition. Although task based instruction provides a medium for acquiring the communicative language, it suffers from a number of oversimplifications. The potentials of each task type in creating such a medium were not investigated in exhaustive detail, and it is left as a potentially interesting topic for further research. This paper reports the analysis of the negotiation of meaning produced by eight intermediate EFL students engaged in required and optional information exchange tasks in dyads. The results show that pushed output has different quality in these different task types meaning whereas required information exchange task provided a medium for more incidence of negotiation work, optional information exchange tasks engaged participants more with discourse work and led to more incidence of the clarification request as an interactional move that has a facilitative role in pushed output. Test constructors and materials developers need to take principled decisions in what to be included in the tests and texts.
\end{abstract}

Keywords: negotiation of meaning, different task types, discourse markers, pushed output

\section{Introduction}

Task-based research has been motivated by Vygotskian accounts of language learning, input, and interactional hypothesis. The Zone of Proximal development (ZDP) is a newly developed construct in SLA in which the emphasis is on the social interaction through which more competent learners provide assistance for less able others as they engage in learning activity. Through this interaction learners will be oriented towards productive rather than reproductive knowledge (Kinglier, 2002). This construct associates with the work of Widdowson (1990). He focuses on the distinction which should have been drawn between training and education. Any educational system should extend learner's learning potentials to cop with problems which do not have a ready-made formulaic solution rather then imposing them to develop a set of principles and formulas for controlling language learning behavior.

The next areas of consideration in task based research are the need for the input and interaction. Theories of L2 acquisition acknowledge the importance of input and interaction but they differ in the extent to which they emphasize the role of input and interaction or combination of both. There are three important views about their roles, the behaviorist, the mentalist, and the interactionist (Ellis, 1994).

For behaviorist, there is a direct relation between input and output. Input is comprised of stimuli and feedback. This view emphasizes the importance of appropriate stimuli and the presence of reinforcement as feedback in language acquisition. Acquisition is thus controlled by external factors.

Mentalist theories emphasize the importance of the learner's black box. Although input is still seen as essential factor for L2 acquisition, it is seen as only a trigger that sets off internal language processing. Input is necessary as a source and what is learned is determined by the cognitive processes happening in the mind.

Interactional models have been applied to two rather different types of theories. According to cognitive interactionist theories, acquisition is the end result of the interaction between the linguistic environment and the learners' internal mechanism. Input has a necessary role but within the constraints of internal mechanisms. The second type of interactional theory towards language is more social in nature. Input is necessary but the source of input is the verbal interaction between the society members which enhances the nature of input for acquisition. Language can't be prescribed as certain set of sentence patterns, vocabularies, functions, and notions. Language changes in the course of interaction and learners should learn language as it is constructed in communication. Therefore, mastery of language can't be achieved through mastery of bits of language, it is claimed that because of cooperation, collaboration, authentic tasks, and negotiation of meaning, good language mastery is achieved.

Gass, Mackey, and Pica (1998) summarize a number of studies that have shown interactional modifications through negotiation for meaning can have a positive effect on the quality of learners' immediate production. It is claimed that in task- based instruction because of negotiation of meaning and being in interaction, learners will develop language proficiency. Tasks, which stimulate negotiation and through that provide comprehensible input and feedback, and push 
learners to reformulate their language, are the ones that will work best for acquisition. Therefore, it seems that exploring the tasks that promote more units of negotiation of meaning is highly significant.

Negotiation of meaning is called upon Krashen's notion of comprehensible input. Therefore, for an input to be acquired, it should be a little beyond learners' current level of competence and it becomes the optimal competence through negotiation of meaning and learners' attempts to make it more comprehensible to ensure mutual understanding.

Negotiation of meaning is defined as the instances in which interlocutors in a conversation face a problem in understanding and they engage in a reciprocal work to solve the comprehension problem or to stop the flow of the conversation to check whether their interlocutor is following the flow of the conversation through interactional modification including comprehension checks, clarification requests, confirmation checks and recast (Ellis, 2003; Ellis \& Barkhuizen, 2005; Ellis, 1994; Oliver, 2002; Oliver, 1998; Pica, Young, \& Doughty, 1987; Gass \& Polio, 1998; ).

Varonis and Gass (1985, cited in Ellis \& Barkhuizen, 2005) outline the structure of negotiation sequence in terms of the following categories:

1. Trigger (i.e., the utterance that causes the communication problem)

2. Indicator (i.e., the utterance that demonstrates a communicative problem has occurred)

3. Response (i.e., the utterance that attempts to address the communication problem identified in the indicator

4. Reaction (i.e., the utterance that indicates a speaker's uptake to the response).

To deal with this kind of sequence, Varonis and Gass (1985 as cited in Ellis \& Barkhuizen, 2005) point out that reaction is an optional element in negotiation sequence. It means that the speaker's response can stimulate a further trigger and as a result, it is possible for one negotiation sequence to consist of several negotiation exchanges (Ellis \& Barkhuizen, 2005).

Researchers have tended to focus on a fairly narrow set of strategies used in these sequencing, using counts of these as measures of the extent to which different tasks promote negotiation. Four strategies have been investigated using the data from the present research.

1. Comprehension checks refer to any expressions designed to establish whether what the interlocutor meant has been understood correctly by the addressee.

A: He has curly hairs

B: No, He has soft hair I mean not curly. Ok? $\rightarrow$ (Trigger)

A: Ok, In mine is curly $\rightarrow$ (Indicator)

$\mathrm{B}$ : So, that is one of the differences $\rightarrow$ (Response to the trigger)

A: yes, let's check it $\rightarrow$ (Reaction)

2. Clarification requests refer to any expressions designed to elicit more information for clarification of the previous utterance. They are mainly formed by yes-no questions and uninvited tag questions.

A: when you speak do you translate from your mother language to

English? $\rightarrow$ (Trigger)

B: I didn't get the point $\rightarrow$ (Indicator)

A: you know we have different cultures. We translate sentences in our language and when we want to speak we translate to English $\rightarrow$ (Response to the trigger)

B: yes, I know it but sometime we need in some situations $\rightarrow$ (Reaction)

A: but most of the students do. If they speak English every day, they can solve the problem

3. Confirmation checks refer to any expressions designed to confirm whether they understood the previous utterance correctly.

A: I am sorry there isn't any discount just the yellow one has $\rightarrow$ (Trigger)

B: So, there is any discount yes? $\rightarrow$ (Indicator)

A: Yes, only the yellow one $\rightarrow$ (Response to the trigger)

$\mathrm{B}: \mathrm{OK} \rightarrow$ (Reaction)

4. Recast refers to any utterances that are rephrased by changing some parts while the focus is still on the meaning.

A: Did she wear glass? $\rightarrow$ (Trigger) 
B: Glasses $\rightarrow$ (Indicator)

A: Yes, Glasses $\rightarrow$ (Response to the trigger)

The most valuable way in which input is made comprehensible is through interactional adjustments. Interactional adjustments are the attempts of learners and their conversation partners to overcome comprehension difficulties in order to make it more comprehensible (Foster \& Ohata, 2005). In these negotiation problems, utterances are checked, repeated, clarified, or modified in some ways through interactional modifications that are used to provide the i+1 input which has facilitative role in language development. Moreover, they provide learners with negative evidence about their own output, and push them to modify it to make it more comprehensible and more target-like (Foster \& Ohato, 2005).

The main objective of the study is whether or not two different task types can provide different interactional context and if so, how these different tasks contribute to different learning opportunities. Interactional context can be examined quantitatively by analyzing incidences of negotiated units in theses different tasks types. The quality of negotiated discourse can be analyzed in terms discourse strategies, and negotiation types (Nakahama, Y., Van Lier, L., \& Tyler, A., 2001). This objective has been addressed by following research questions:

1. Is there any statistically significant difference between the required information exchange tasks and optional information exchange tasks in terms of the quantity of negotiation of meaning?

2. Is there any statistically significance difference between required information exchange tasks and optional information exchange tasks in terms of the quality of negotiation of meaning in terms of the discourse strategies?

3. Is there any statistically significance difference between required information exchange tasks and optional information exchange tasks in terms of the quality of negotiation of meaning in terms of the negotiation types?

\section{Method}

The main objective of this study was to find out whether there is any statistically significant difference between the quantity and quality of negotiation units in the required information exchange tasks and optional information exchange tasks. To come up with an answer to this question, the researcher conducted an interview with three trained raters. From among 20 invited participants; eight participants were selected for the study as they fulfill the statistical requirements of homogenous group by having a score within one standard deviation (9) above and below the mean (67) as measured by FSI rating scale. The inter-rating reliability among three raters in determining participants' proficiency level was calculated by the Spearman-Brown Prophecy formula (0.85). Prior to conducting the research, the participants were informed about what they were going to go through. They had been given a checklist in order to determine their background knowledge and the tasks that they were more confident at (topic familiarity). The sample tasks were taken from the materials that the participants had studied on the basis of their' answers to the mentioned checklist. Then, the teachers were given the sample tasks and asked to evaluate the tasks according to the checklist provided to determine the appropriateness of tasks for the intended participants taken from the study by Nunan (1989). A pretest of tasks was administered by a similar group to the intended one selected on the basis of their scores in the interview. The purpose of pretest was to see whether tasks would lend themselves for negotiation of meaning. By so doing, the researcher could have reliable sources for decision making based on the selected tasks.

To come up with reliable sources for identification of negotiation units, the researcher selected two raters that had the same understanding of negotiation of meaning. They were introduced with the framework for the analysis of the structure of negotiation sequences proposed by Varonis and Gass (1985 as cited in Ellis \& Barkhuizen, 2005). If the raters found the same units of negotiation of meaning in the pretest, they would serve as reliable sources for identification of units of negotiation of meaning. Two trained raters independently coded the transcription for trigger types and negotiation cycle. Inter-rater reliability for trigger types was calculated to indicate the reliability of the procedure in identification of negotiation units and appropriateness of the tasks for the purpose of the study. After the selection of the task and raters, participants were paired according to their interest as they were all at the intermediate level of language proficiency. Each participant was asked to work with his or her partner. The tasks were introduced to the participants by their teacher. In order to reduce stress, the teacher was trained to run a warm up before performing the tasks. Participants were encouraged to ask questions if they had problems in comprehending each task and the procedure in each task. First, participants were asked to work on the required information task. After completing the first task, they were asked to work on the optional information exchange task, their performances on the optional information exchange tasks and required information exchange tasks were audio-taped for data analysis.

The data were analyzed quantitatively in order to identify different ways in which repair negotiation took place in optional information exchange tasks and required information exchange

tasks. For establishing comparability, all interactions were normalized to 10 minutes. For the quantitative analysis, first, the signal (the head of negotiation sequence), such as a clarification request was identified. Then, looking back from the signal, an earlier utterance was coded as the trigger. To compare the mean frequencies of negotiation in two different types of interaction, the researcher used t-test, treating occurrences like test scores and calculating a mean for each type of interaction (required information exchange and optional information exchange). Comparing the quantity of repair negotiation across tasks thus does not seem to tell the whole story. The data were quantitatively analyzed to explore the discourse strategies, and negotiation types in interactions developed by each type of tasks. 


\subsection{Pretesting Required Information Exchange Tasks and Optional Information Exchange Tasks}

The tasks were pretested by two participants similar to the intended participants on the basis of their scores in the interview. The participants' performances were audio-taped. Two trained raters transcribed participants' performances and analyzed them to find negotiation units by considering each negation unit as a test score. The descriptive statistics on raters' finding the negotiation units is displayed in Table 1 (required information exchange tasks) and Table 2 (optional information exchange tasks). The correlations between raters on finding negotiated units are depicted in Table 3 (required information exchange tasks) and Table 4 (optional information exchange tasks).

$\underline{\text { Table 1. Descriptive Statistics on required information exchange tasks (pretest) }}$

\begin{tabular}{llll}
\hline & Mean & Std. Deviation & $\mathrm{N}$ \\
\hline RATER1 & 9.00 & 4.53 & 8 \\
RATER2 & 8.87 & 4.58 & 8 \\
\hline
\end{tabular}

Table 2. Descriptive Statistics on optional information exchange tasks (pretest)

\begin{tabular}{llll}
\hline & Mean & Std. Deviation & $\mathrm{N}$ \\
\hline RATER1 & 10.71 & 6.26 & 7 \\
\hline RATER2 & 10.28 & 5.58 & 7 \\
\hline
\end{tabular}

Table 3. Inter-rater reliability in finding negotiation units in required information exchange tasks (pretest)

\begin{tabular}{llll}
\hline & & RATER1 & RATER2 \\
\hline RATER1 & Pearson Correlation & 1 & .956 \\
\hline & Sig.(2-tailed) &. & .000 \\
\hline & $\mathrm{N}$ & 8 & 8 \\
\hline RATER2 & Pearson Correlation & .956 & 1 \\
\hline & Sig.(2-tailed) & .000 &. \\
\hline & $\mathrm{N}$ & 8 & 8 \\
\hline
\end{tabular}

Table 4. Inter-rater reliability in finding negotiation units in optional information exchange tasks (pretest)

\begin{tabular}{llll}
\hline & & RATER1 & RATER2 \\
\hline RATER1 & Pearson Correlation & 1 & .974 \\
\hline & Sig. (2-tailed) &. & .000 \\
\hline RATER2 & $\mathrm{N}$ & 7 & 7 \\
\hline & Pearson Correlation & .974 & 1 \\
\hline & Sig. (2-tailed) & .000 &. \\
\hline & $\mathrm{N}$ & 7 & 7 \\
\hline
\end{tabular}

These are estimates of the reliabilities for each set of rating as they were assigned by the raters in the pretest phase. Since these estimates are the reliability of each single set of rating, and since two or three sets of ratings are likely to be higher in reliability when taken together, adjusting to find the reliability of larger number of ratings taken together would be logical, possible, and advisable. The Spearman-Brown Prophecy formula can be used for this purpose. The adjustment can be applied to any one of the coefficients reported in Table 3, but careful approach to all statistics is to use the lowest estimate. The Spearman-Brown Prophecy formula was applied as follow to find the inter- reliability of raters in finding negotiation units in pretesting required information exchange tasks:

$$
\begin{gathered}
r x x=\frac{n \times r}{(n-1) r+1} \\
r x x=\frac{2 \times 0.95}{(2-1) 0.956+1}=0.97
\end{gathered}
$$

The Spearman-Brown Prophecy formula was applied as follow to calculate the inter-rater reliability in finding negotiation units in optional information exchange tasks in pretest phase using the lowest estimate Table 4.

$$
r x x=\frac{n \times r}{(n-1) r+1}
$$




$$
r x x=\frac{2 \times 0.974}{(2-1) 0.974+1}=0.98
$$

Since the reliability estimate is close to one as the ideal estimate, it can be concluded that the rating procedure adapted by the trained raters to find negotiation units and tasks themselves as the appropriate medium for these negotiation units can be a sound source for reliable information

and decision making. Since the mean score for the negotiation units in required information exchange tasks was 8.87 and the standard deviation was calculated to be 4.58 (recalling Table 2), the tasks which can lend themselves to produce negotiation units to the extent of one standard deviation above the mean and one standard deviation below the mean were selected to be used at the main study.

$\mathrm{X}+1 \mathrm{SD} \rightarrow 8.87+4.38=13.21$

$\mathrm{X}-1 \mathrm{SD} \rightarrow 8.87-4.38=4.49$

Thus, the required information exchange tasks that lend themselves to create 4-13 negotiation units and more were selected to be maneuvered on at the present study. Since the mean score for the negotiation units in optional information exchange tasks was 10.28 and the standard deviation was calculated to be 5.58 (recalling Table 3 ), the tasks which can lend themselves to produce negotiation units to the extent of one standard deviation above the mean and one standard deviation below the mean were selected to be used at the main study.

$\mathrm{X}+1 \mathrm{SD} \rightarrow 10.28+5.58=15.86$

$\mathrm{X}-1 \mathrm{SD} \rightarrow 10.28-5.58=4.7$

Thus, the optional information exchange tasks that lend themselves to create 4-15 and more negotiation units were selected to be maneuvered on at the present study.

From among the tasks that were pretested, three required information exchange tasks (one spot the difference and two information gap tasks with 9,16, and 13 index of negotiation units) and three optional information exchange tasks (two opinion exchange tasks and one decision making task with 14, 6, and 5 index of negotiation units) were selected for the study. Having assigned participants into pairs, the teacher asked them to work on the selected required and optional information exchange tasks separately in different sessions. Their performances were audiotaped for further analysis.

\section{Results}

To analyze the data gathered on participants' performance, a number of t-tests were used to compare the mean score of the occurrence of negotiation units in required information exchange tasks and optional information exchange tasks as far as the quantity of negotiation units and the mean score of discourse strategies, and negotiation types in each task typology as far as the quality of negotiated discourse was concerned.

\subsection{Comparing the quantity of negotiation units in two task types}

T-test was conducted to calculate the mean differences between the negotiation units in required and optional information exchange tasks. The results of participants' performances on the tasks are displayed in Table 5 and Table 6.

Table 5. Paired samples statistics on negotiation units in two task types

\begin{tabular}{llllll}
\hline & & Mean & $\mathrm{N}$ & Std. Deviation & Std. Error Mean \\
\hline Pair 1 & REQUIRED & 22.25 & 4 & 8.99 & 4.49 \\
\hline & OPTIONAL & 14.75 & 4 & 6.29 & 3.14 \\
\hline
\end{tabular}

Table 6. Paired Samples test on negotiation units in two task types

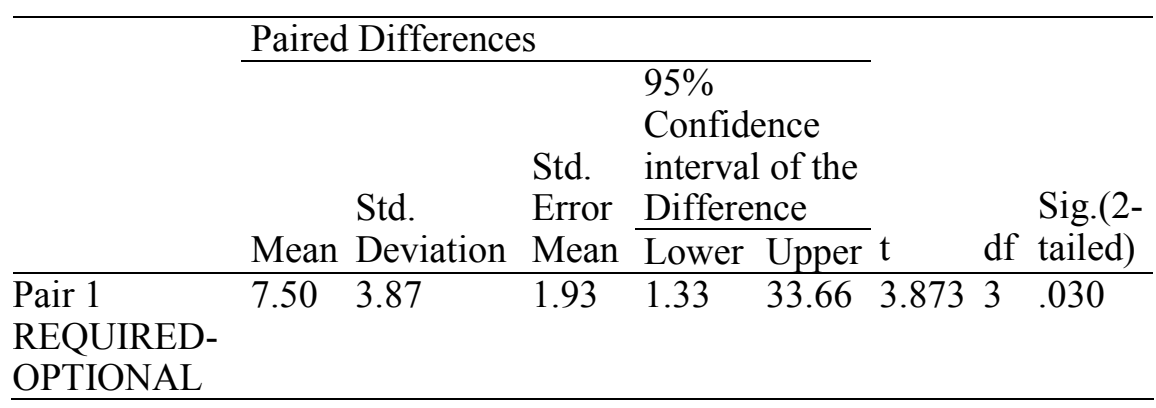

In Table 6, the final column is the research's probability value. This value is less than 0.5 . It can be concluded that there is a significant difference between two task types. Having established that there is a statistically significant difference between required information exchange tasks and optional information exchange tasks, the researchers ran the next step to find out in which task types participants created more negotiation units. To do this, Table 5 is reviewed. This Table gives the mean score for each of the two sets of scores which are paralleled to negotiation units. The mean 
of negotiation units in required information exchange was 22.25 and the mean score of negotiation units in optional information exchange tasks was 14.75 . Therefore, it can be concluded that there was significant difference in the number of the negotiation units in each task types, approving that negotiation units were created more in required information exchange tasks than optional information exchange tasks.

Although the result presented in Table 6 show that the difference obtained in the two sets of scores (negotiation units) was unlikely to occur by chance, it does not tell us much about the magnitude of this difference. One way to find out about the magnitude of the difference is to calculate an effect size statistic (Pallant, 2001). The procedure for calculating and interpreting

Eta squared (one of the most commonly used effect size statistic) can be obtained using the following formula:

Eta Squared $=\frac{t^{2}}{T^{2}+N-1}=\frac{(3.873)^{2}}{(3.873)^{2}+4-1}=\frac{15.00}{15.00+4-1}=0.83$

To interpret the Eta squared values, the following guidelines can be used (Pallant, 2001). The magnitude of 0.01equals small effect, 0.06 equals moderate effect, and 0.14 equals large effect. Given this study's Eta squared value of 0.83 , we can conclude that there was a large effect, with a substantial difference in the amount of negotiation units in each task typology.

\subsection{Comparing two task types in terms of negotiated discourse}

As mentioned before, comparing task types in terms of the quantity of negotiation each task type lends itself to, as an important factor in determining effectiveness of a task in learning, masks other important discourse dynamics, and therefore, masks important learning opportunities beyond the ideational or informational level. For this reason, the discourse that the tasks as a medium create must be analyzed qualitatively to ensure any differences. In this study, Negotiated discourse was analyzed in terms of two factors; discourse markers, and negotiation types (Swain, 1985 as cited in Nakahama, Y., Van Lier, L., \& Tyler, A., 2001).

\subsubsection{Discourse strategies in two task types}

Comparing the occurrence of discourse strategies in two different task types can provide us information about how participants check each others understanding to ensure mutual understanding (Nakahama, Y., Van Lier, L., \& Tyler, A., 2001).

T-test was used to compare the mean number of discourse strategies in required information exchange tasks and optional information exchange task. The result of t-test is depicted in Table 8. The descriptive statistics of this analysis is displayed in Table 7.

Table 7. Paired Samples Statistics on the discourse strategies in two task types

\begin{tabular}{llllll}
\hline & & Mean & $\mathrm{N}$ & Std. Deviation & Std. Error Mean \\
\hline Pair 1 & REQUIRED & 7.00 & 4 & 2.16 & 1.08 \\
\hline & OPTIONAL & 16.25 & 4 & 3.30 & 1.65 \\
\hline
\end{tabular}

Table 8. Paired Samples Test on the discourse strategies in two task types

\begin{tabular}{|c|c|c|c|c|c|c|c|c|}
\hline & \multicolumn{5}{|c|}{ Paired Differences } & \multirow[b]{3}{*}{$\mathrm{t}$} & \multirow[b]{3}{*}{$\mathrm{df}$} & \multirow[b]{3}{*}{$\begin{array}{l}\text { Sig.(2- } \\
\text { tailed) }\end{array}$} \\
\hline & \multirow[b]{2}{*}{ Mean } & \multirow[b]{2}{*}{$\begin{array}{l}\text { Std. } \\
\text { Deviation }\end{array}$} & \multirow{2}{*}{$\begin{array}{l}\text { Std. } \\
\text { Error } \\
\text { Mean }\end{array}$} & \multicolumn{2}{|c|}{$\begin{array}{l}95 \% \text { Confidence } \\
\text { interval of the } \\
\text { Difference }\end{array}$} & & & \\
\hline & & & & Lower & Upper & & & \\
\hline $\begin{array}{l}\text { Pair } 1 \\
\text { REQUIRED- } \\
\text { OPTIONAL }\end{array}$ & -9.25 & 4.78 & 2.39 & -16.86 & -1.63 & -3.86 & 3 & .031 \\
\hline
\end{tabular}

To come up with an answer to the second research question, Table 8 should be reviewed. As it is reported in this question the sig value (.031) is smaller than 0.5 . Thus, it can be concluded that there is a significance difference between the required information exchange tasks and optional information exchange tasks in terms of the created discourse strategies. To see in which task interlocutors used more discourse strategies, the researcher recalled Table 7. The mean number of the occurrence of discourse strategies in optional information exchange tasks was greater (16.25) than that of required information exchange tasks (7.00). By the same token, interlocutors used more discourse strategies to have connected speech in optional information exchange tasks than required information exchange tasks.

\subsubsection{Negotiation types in required information exchange tasks and optional information exchange tasks}

It has been argued that some types of negotiation (such as clarification requests) promote pushed output (Swain 1985, 
cited in Nakahama, Y., Van Lier, L., \& Tyler, A., 2001). For example, confirmation check and recast do not require nonnative speakers to formulate their own speech or that of others whereas open-ended clarification requests by native speakers encourage the non-native speaker to modify a previous utterance. T-test was used to compare the mean number of occurrence of clarification request as a type of interactional modification that works the best for providing learning opportunities in each interaction. The result of $t$-test is depicted in Table 10 and descriptive statistics of this analysis is displayed in Table 9.

Table 9. Paired Samples Statistics on the clarification requests in required information exchange tasks and optional information exchange tasks

\begin{tabular}{llllll}
\hline & & Mean & $\mathrm{N}$ & Std. Deviation & Std. Error Mean \\
\hline Pair 1 & REQUIRED & 3.50 & 4 & 2.08 & 1.04 \\
\hline & OPTIONAL & 8.25 & 4 & .957 & 0.47 \\
\hline
\end{tabular}

Table 10. Paired Samples Test on the clarification requests in required information exchange tasks and optional information exchange tasks

\begin{tabular}{|c|c|c|c|c|c|c|c|c|}
\hline & \multicolumn{5}{|c|}{ Paired Differences } & \multirow[b]{3}{*}{$\mathrm{t}$} & \multirow[b]{3}{*}{$\mathrm{df}$} & \multirow[b]{3}{*}{$\begin{array}{l}\text { Sig.(2- } \\
\text { tailed) }\end{array}$} \\
\hline & \multirow[b]{2}{*}{ Mean } & \multirow[b]{2}{*}{$\begin{array}{l}\text { Std. } \\
\text { Deviation }\end{array}$} & \multirow{2}{*}{$\begin{array}{l}\text { Std. } \\
\text { Error } \\
\text { Mean }\end{array}$} & \multicolumn{2}{|c|}{$\begin{array}{l}95 \% \text { Confidence } \\
\text { interval of the } \\
\text { Difference }\end{array}$} & & & \\
\hline & & & & Lower & Upper & & & \\
\hline $\begin{array}{l}\text { Pair } 1 \\
\text { REQUIRED- } \\
\text { OPTIONAL }\end{array}$ & -4.75 & 1.70 & 0.85 & -7.46 & -2.03 & -5.56 & 3 & 0.011 \\
\hline
\end{tabular}

Table 10 shows that the sig value $(0.011)$ is smaller that 0.5 . Therefore, the third research question can be answered. To see in which task interlocutors created more clarification request, the researcher recalled Table 9 . The mean number of the occurrence of clarification request in optional information exchange tasks was greater (8.25) than that of required information exchange tasks (3.50). By the same token, interlocutors created more clarification request in optional information exchange tasks than in required information exchange tasks.

\section{Discussion \& Conclusion}

Having analyzed the mean scores of negotiation units in required information exchange tasks and optional information exchange tasks, the researcher found that these two different task typologies created a different medium for interaction to task place. Required information exchange tasks had more potential for creation of negotiation units.

SLA researchers have focused on repair negotiations as a locus for noticing to take place as the learners notice the gap between the current interlanguage and the target language they intend to learn. Thus, the more repair negotiations, the more opportunities for comprehension and learning. If in the present analysis the researcher had attended only to the amount of repair negotiations, the data would support the assertion that required information exchange tasks provide more learning opportunities than optional information exchange tasks do, as the required information exchange tasks triggered more instances of repair.

Subsequent analysis examined important discourse dynamics to reveal important learning opportunities beyond the ideational or informational level.

As the importance of negotiation of meaning was discussed before, one may think that required information exchange tasks are the ideal language learning tasks for learning to take place. But, by analyzing the quantity of negotiation units in required information exchange tasks and optional information exchange tasks, one can't approve such a claim.

While there is research to support the premise that tasks which involve in plentiful negotiation of meaning create the conditions needed for acquisition, there are alternative theoretical premises that emphasize other aspects of language use, for example, learner output or pushed output. One of the aspects that are used in qualifying learner language is the discourse markers. Therefore, it was used to draw the differences between two types of tasks along the continuum. Having run the analysis, the researcher statistically approved that the participants created more discourse strategies in optional information exchange tasks. This must be taken into account when the objective of any educational system is providing opportunities for language learners to practice more extended language.

The first factor on the basis of which two types of interactions in two different task types were analyzed was the number of the discourse strategies that participants use to connect the constituents of the interaction to each other for ensuring mutual understanding, checking whether their interlocutors were following what they were discussing and incorporating what they were discussing to what they had already discussed. As it was mentioned, interlocutors used more discourse strategies to create coherent discourse in optional information exchange tasks than required information exchange tasks. In Line with the results of the study by Nakahama, Y., Van Lier, L., \& Tyler, A., (2001) pragmatic particles in required information exchange tasks had completely different functions than in optional information exchange tasks. In required information exchange tasks, they were used by the interlocutors to signal to the other interlocutor that they understood 
the point and were ready to go to the next item of the task whereas in optional information exchange tasks, they were mainly used to check the interlocutors comprehension and to see if he is following the flow of the conversation.

The second factor on the basis of which two types of interaction in two different task types were analyzed was the number of occurrence of clarification request. As mentioned before, clarification request is statistically approved to be the best working move in providing learning opportunities. In this study, two types of tasks namely required information exchange tasks and optional information exchange tasks were compared on a number of grounds. As t-test was conducted, it was approved that interlocutors created more clarification requests in optional information exchange tasks than in required information exchange tasks.

One point worthy to mention is that the number of the confirmation checks as one of the interactional modification was much greater in required information exchange tasks than in optional information exchange tasks. The other important point is that, although it was not statistically significant, the number of the occurrence of recast in required information exchange tasks was much greater than that in optional information exchange tasks.

A number of studies have shown that required information exchange tasks triggers more repair negotiation than optional information tasks; it is widely presumed that required information interactions tend to push learners to produce more interlanguage. This perception is supported by Long's (1983 as cited in Nakahama, Y., Van Lier, L., \& Tyler, A., 2001) claim that in optional information exchange tasks learners and their interlocutors can use avoidance strategies to avoid communicating on problematic topics and therefore, avoid repair negotiation and pushed output. In contrast to this presupposition, the data in the present study indicate that the optional information exchange tasks can provide instances and desired opportunities for pushed output.

The case for including an introduction to the principles and techniques of task based teaching in teacher training and teacher education program is important (Ellis, 2003). Such introduction makes teachers and implementers of task based instruction informed about the effectiveness of task-based instruction and implementational factors that affect these effectiveness and ovoid the oversimplifications in this field. If a task is used to examine test- takers' ability and to generalize the test results from context to context, it will be necessary to understand how the choice of task influences the way the testee performs. Great care must be taken in generalizing from context to context, as performance on one particular kind of task will not necessarily be matched by performance on the different kind. Materials and curriculum developers need to take principled decisions about what kinds of tasks to include in the course, the balance of the different types of tasks, and the sequencing of the tasks (Bygate, 1999).

The limited number of the participants in this study limits the generalizability of the results. The study needs to be repeated with more participants. There is a subset of research on negotiation of meaning in adult curriculum. Finding the difference in the way that children run the negotiation for meaning and with that of adults is worthy to study as adults scaffold children in language learning. Individual differences are one of the factors which may contaminate the results of the study. It is highly recommended to conduct a set of studies to find the effect of individual difference on negotiation of meaning in each task typology.

\section{References}

Bygate, M. (1999). Quality of language and purpose of task: patterns of learner's language on two oral communication tasks. Language Teaching Research 3 (3), 185- 214.

Ellis, R. (1994). The study of second language acquisition (1 $1^{\text {st }}$ ed.). Oxford: Oxford University Press

Ellis, R. (2003). Task- based language teaching and learning ( $1^{\text {st }}$ ed.). Oxford: Oxford University press

Ellis, R., \& Barkhuizen, G. (2005). Analyzing learner language ( $1^{\text {st }}$ ed.). Oxford: Oxford University Press.

Ellis, R. (2005). Measuring implicit and explicit knowledge of a second language. Studies in Second Language

Acquisition 27, 141-172

Foster, P., \& Ohta, M. (2005) Negotiation for meaning and peer Assistance in second language classroom. Applied linguistics 26 (3), 402-430.

Gass, S., \& Polio, C. (1998). The role of interaction in native speakers' comprehension of non native speaker speech.

The Modern Language Journal. 82 (3), 308-319.

Gass, S., Mackey, A., \& Pica, T. (1998). The role of input and interaction insecond language acquisition: introduction to the special issue.The modern Language Journal, 82 (3), 299-307

Kinginger, C. (2002). Defining the zone of proximal development in US foreign language education. Applied

Linguistics 23 (2), 240-261.

Nakahama, Y., Van Lier, L., \& Tyler, A. (2001). Negotiation of meaning in conversational information gap activities: a comparative discourse analysis. TESOL Quarterly 35 (3), 377-405.

Nunan, D. (1989). Designing tasks for the communicative classroom. Cambridge University Press

Oliver, R. (1998). Negotiation of meaning in child interactions. The Modern Language Journal, 82 (3), 372-382

Oliver, R. (2002). The patterns of negotiation of meaning in child interactions. The Modern Language Journal, 86 (1), 97-111.

Pica, T., Young, R., \& Doughty, C. (1987). The impact of interaction on comprehension. TESOL Quarterly, 21 (4), 737-755.

Pallant, J. (2001). SPSS Survival Manual. Open University Press. Buckingham. Philadelphia.

Widdowson, G. H. (1990). Aspects of language teaching. Oxford: Oxford University Press. 


\section{Appendix A}

Topic Familiarity Questionnaire

Which activities are you confident at?

Choose from the highest confidence to the lowest

\begin{tabular}{|l|l|l|l|}
\hline & 1 & 2 & 3 \\
\hline 1. Give suggestions and decide on the best suggestion & & & \\
\hline 2. Giving reasons & & & \\
\hline 3. Giving instructions & & & \\
\hline 4. Making decisions & & & \\
\hline 5. Solving problems & & & \\
\hline 6. Describing people & & & \\
\hline 7. Telling stories & & & \\
\hline 8. Completing incomplete set of information & & & \\
\hline 9. Organizing information & & & \\
\hline 10. Giving directions & & & \\
\hline
\end{tabular}

\section{Appendix B}

Task Evaluation Questionnaire

1. To what extent is the goal or goals of the task obvious a) to you b) to your students?

2. Is the task appropriate to the learners' proficiency level?

3. To what extent does the task reflect a real-world or pedagogic rational? Is this appropriate?

4. Is the task likely to be interesting and motivating to the students?

5. Is there an information gap or problem which might promote a negotiation of meaning?

6. Are the activities designed in a way which will allow learners to communicate and cooperate with others?

7. To what extent are learners encouraged to negotiate meaning?

8. Is the task at the appropriate level of difficulty for students?

9. If not, is there any way in which the task might be modified in order to make it either easier or more challenging?

10. Is the task realistic in terms of the resources and teacher-expertise it demands?

\section{Appendix C: Sample Optional Information Exchange Task (Opinion Exchange Task)}

(Student A looks at this page. Student B looks at page 114.)

Part 1 Read the survey on the topic of learning English. Write A if you agree, c $D$ if you disagree.

\begin{tabular}{l} 
Listening to English is easier than reading it. \\
The most difficult thing about listening to English is \\
the pronunciation. \\
If I can't understand all the words, I start to feel anxious. \\
When I listen to someone speaking, I find it difficult to \\
respond immediately. \\
When I listen to English, it is quite easy to pick out the \\
main ideas. \\
$\begin{array}{l}\text { Asking questions helps me understand what someone is } \\
\text { saying. }\end{array}$ \\
\hline $\begin{array}{l}\text { Listening to the TV or radio needs different skills from } \\
\text { listening to someone speaking. }\end{array}$ \\
\hline Learning in a group helps me improve my listening skills.
\end{tabular}


Part 2 Interview Student B. Ask for reasons for his or her opinions. Make notes about your partner's reasons. Agree or disagree and respond with your own reasons. Reverse roles. Student B will interview you about learning English. Give reasons for your opinions.

(Student B looks at this page. Student A looks at page 103.)

Part 1 Read the survey on the topic of learning English. Write A if you agree, or $D$ if you disagree.

\begin{tabular}{l} 
It is easier to speak English than to write it. \\
The most difficult thing about speaking English is \\
the pronunciation. \\
It doesn't matter if I make mistakes when I am speaking \\
English, as long as people understand me. \\
To speak English well, I need a large vocabulary. \\
If I am good at grammar, I will be able to speak English well. \\
When I speak English, I usually translate from my native \\
language in my mind. \\
\hline Reading, listening, and writing in English can help improve \\
my speaking skills.
\end{tabular}

Part 2 Student A will interview you about learning English. Give reasons for your opinions. Reverse roles. Interview Student A. Ask for reasons for his or her opinions. Make notes about your partner's reasons. Agree or disagree and respond with your own reasons.

\section{Appendix D}

(Sample Required Information Exchange Task

Task: $\underline{\text { (Required information exchange task; information gap task) }}$

(Student A looks at this page. Student B looks at page 112.)

Part 1 Look at your map. You are new in town. Ask your partner about these places: cafe, bookstore, post office, bank. Label them on your map. You are both at $x$. 


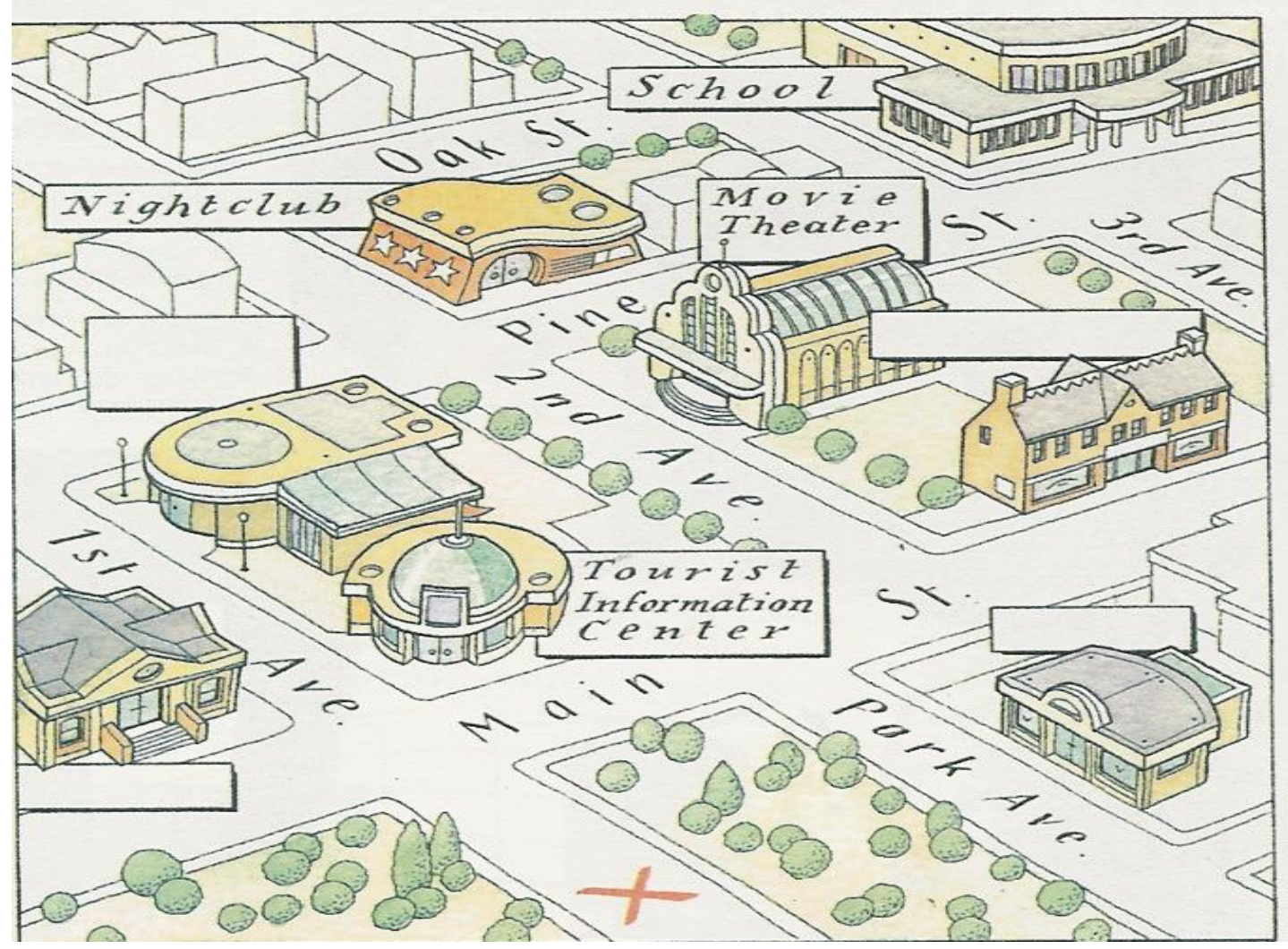

(Student B looks at this page. Student A looks at page 87.)

Part $I$ Look at your map. Your partner is new in town. Answer his or her questions. You are both at $X$.

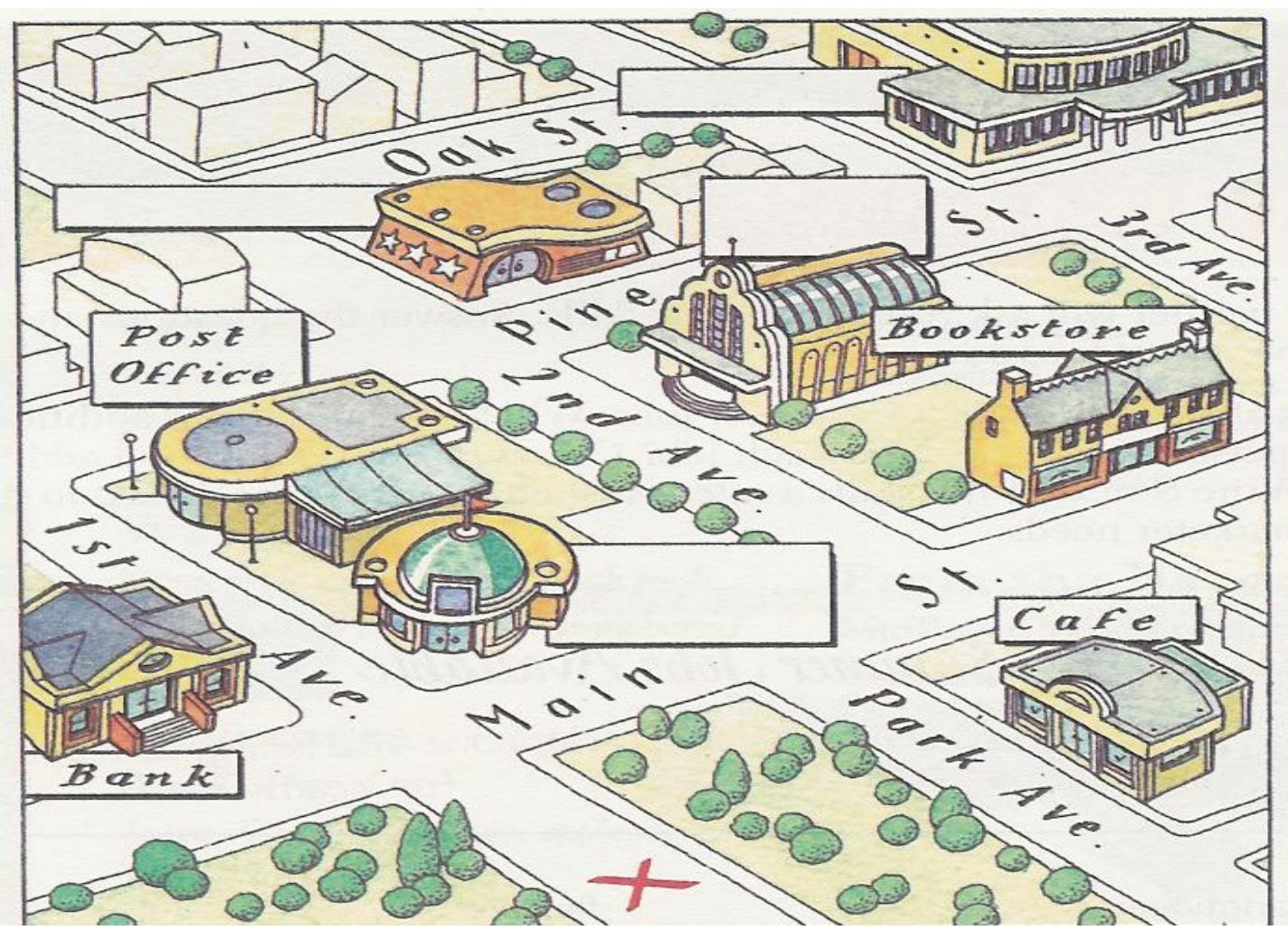

Part 2 Ask your partner about these places: a nightclub, a school, a tourist information center, a movie theater. Label them on your map. 